\title{
Percent Predicted Diffusion Capacity of the Lung for Carbon Monoxide
}

National Cancer Institute

\section{Source}

National Cancer Institute. Percent Predicted Diffusion Capacity of the Lung for Carbon

Monoxide. NCI Thesaurus. Code C120829.

The degree to which inhaled carbon monoxide diffuses from the alveoli into the blood, expressed as a proportion of the predicted normal value. 